\title{
HMGB1 and its physiological and pathological roles
}

\author{
Naglova H, Bucova M \\ Institute of Immunology, Faculty of Medicine, Comenius University, Bratislava, Slovakia. \\ hedviga.kanalikova@fmed.uniba.sk
}

\begin{abstract}
HMGB1 has been formerly known for its intracellular function - as the intranuclear non-histone DNA binding protein, which contributes to stabilization of nucleosomes, mediation of DNA bending and is regarded to have an essential position in DNA repair. Lately, its participation in innate and specific immune responses has been revealed. Passively released from necrotic cells or actively produced by various cell types it acts as an alarmin and is responsible for production of pro-inflammaory cytokines. HMGB1 is able to interact with RAGE and TLRs, receptors that belong into family of pattern recognition receptors and are involved in activation of pathways leading to production of pro-inflammatory cytokines. Its key role has been revealed in mediation of sepsis and as it is released later than other pro-inflammatory cytokines it became known as a "late mediator of sepsis". HMGB1 also contributes to the development of atherosclerosis and autoimmune diseases, e.g. its association with immunopathogenesis of SLE and RA has been suggested. Beside its negative function, HMGB1 protein seems to be able to attract stem cells to the area of inflammation and thus promotes regeneration processes. This paradoxical function of HMGB1 protein has also been revealed in growth and spread of many types of tumours. HMGB1 represents a potential target in therapy of various disorders related to inflammation (Fig. 2, Ref. 137). Full Text in PDF www.elis.sk.

Key words: atherosclerosis, autoimmune diseases, cancer, HMGB1, inflammation, sepsis.
\end{abstract}

The high mobility group (HMG) nuclear proteins were discovered in 1973 in an attempt to find a better explanation how gene expression is regulated (1). Since then this family of non-histone, chromatin-associated proteins have been considered involved in DNA organization and regulation of transcription. This group of proteins has common structural characteristics unusual to other chromosomal proteins. Long AT-rich 3' untranslated regions as well as highly negatively charged carboxy-terminated regions belong to these different characteristics (2).

The high mobility group box-1 protein (HMGB1), a member of HMG family, was first isolated from perinatal rat brain in 1987. It was found in central neurons, where this heparin-binding protein could support neurite outgrowth (3) Belonging to group of highly evolutionarily conserved and ubiquitous proteins, HMGB1 in mouse has amino acid sequence $100 \%$ identical to amino acid sequence in rat and there is nearly a $99 \%$ identity between rodents and humans (4-6). While in mice HMGB1 gene lies on chromosome 5 (7), in humans the gene is localized on chromosome 13 (8).

HMGB1 was originally found in the nucleus. It was characterized as a 215 amino acid DNA-binding non-histone chromosomal protein, which consists of two positively charged DNA binding domains named HMG box A and box B, and a negatively charged

Institute of Immunology, Faculty of Medicine, Comenius University, Bratislava, Slovakia

Address for correspondence: Naglova Hedviga, MD, Institute of Immunology, Faculty of Medicine, Comenius University, Sasinkova 4, SK-811 08 Bratislava, Slovakia.

Phone: +421.2.59357578, Fax: +421.2.59357578

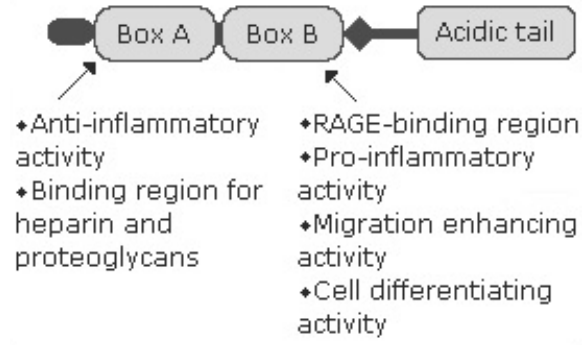

Fig. 1. Structure of HMGB1 protein. Legend: HMGB1 - High Mobility Group Box 1; RAGE - Receptor for Advanced Glycation End-products. HMGB1 protein consists of two positively charged DNA binding domains named HMG box $A$ and box $B$, and a negatively charged $C$ terminal domain that contains 30 repetitive glutamic and aspartic acid residues. Box A is responsible for anti-inflammatory activity of HMGB1 protein and also forms the region for binding of heparin and proteoglycans. Box B except of its pro-inflammatory, migration-enhancing and cell differentiating activity carries also a binding region for RAGE.

C-terminal domain that contains 30 repetitive glutamic and aspartic acid residues (Fig. 1) (9, 10). HMGB1 can bind without sequence specificity to double-stranded, single-stranded as well as misshapen (deformed, distorted) DNA (2, 10-13). Highly affinitive interactions of HMGB1 with nucleosomes lead to the stabilization of their structure and mediation of DNA bending. These interactions also facilitate the binding of transcription factors along with steroid hormone receptors (14), steroid/nuclear hormones progesterone (15) and oestrogen $(16,17)$, HOX proteins (18) and transcription factor IIB (19). HMGB1 is regarded to be a master DNA repair mechanic due to its specific ability to bind to distorted and dam- 


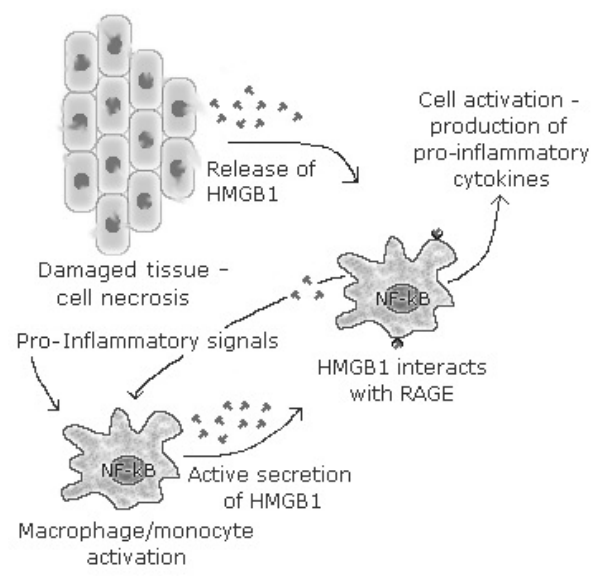

Fig. 2. Active and passive release of HMGB1 protein. Legend: HMGB1 - High Mobility Group Box 1; RAGE - Receptor for Advanced Glycation End-products. Actively (from monocytes/macrophages) or passively (damaged and necrotic cells) released HMGB1 interacts with RAGE on immune cells and activates them. The autocrine effect of HMGB1 enhances its own releasing from activated cells and circulus vitiosus is created - inflammatory response sustains.

aged DNA. Lange and Vasquez also discussed an important role of HMGB1 in the nucleotide excision repair (NER) pathway and discussed aspects of both the "repair shielding" and "repair enhancing" hypotheses. Furthermore, they report recently observed a participation of HMGB1 protein in the base excision repair (BER) pathway and its function in mismatch repair (MMR) (97). On account of HMGB1, the knockout mice died within 24 hours of birth from hypoglycaemia. Therefore, the nuclear role of this protein seems to be indispensable to life (20).

Several cell types are able to produce HMGB1, but their production varies due to development and age of each cell (21). It has been shown that migration of HMGB1 between the cytoplasm and nucleus is possible, and this migration is dependent on the cell cycle phase. In some cell types, HMGB1 was found mainly in the cytoplasm, especially in brain and liver tissue, whilst in lymphoid cells, HMGB1 is located both in the cytoplasm and nucleus $(22,23)$.

\section{Passive release of HMGB1}

HMGB1 is likely to be released into extracellular milieu in two ways - passively from necrotic or injured cells and actively by activated monocytes, macrophages and dendritic cells (DCs) in the area of inflammation or injury (Fig. 2) (88).

Necrotic and damaged cells can passively secrete HMGB1, while apoptotic cells can `t, thus giving a distinct signal to organism, so it can recognize these two types of cell death. Passive release of HMGB1 to extracellular fluid represents a good intracellular signal of tissue injury and a very good „,necrotic marker“, and it results in immunostimulatory, inflammatory and reparative responses. HMGB1 belongs to the group of alarmins - endogenous signals of threat to organism called also damaged associated molecular patterns (DAMPs). It promotes the recruitment of mononuclear cells that clear cellular debris and protects against infection $(24,89,90)$.

In contrast to necrotic cells, in apoptotic cells on the basis of cell death, HMGB1 can not be released to extracellular fluid. Responsible for this distinction between apoptotic and necrotic cells is the chromatin binding affinity of HMGB1. During a whole cell cycle, HMGB1 is not bound to the chromatin of living cells in a tight manner, and association and dissociation can proceed easily. This also allows a passive release of HMGB1 after damage or necrosis of the cell. The intracellular retention of HMGB1 in apoptotic cells is the result of an irreversible association of HMGB1 with one or more hypoacetylated components of chromatin. So after apoptosis, HMGB1 can induce only negligible inflammation in the surrounding tissue $(24,88,91)$.

\section{Active production of HMGB1}

Apart from a passive releasing from necrotic or damaged cells, HMGB1 can be also secreted actively. As a consequence of exogenous bacterial stimulation, e.g. lipopolysacharide (LPS) or stimulation coming from pro-inflammatory cytokines, such as TNF, IL-1 and also HMGB1 itself, HMGB1 is actively secreted from macrophages, monocytes, dendritic cells and many other components of innate immune system. Activated leucocytes secrete HMGB1 actively through processes that are routed differently from classical pathways of secretion, i.e. through endoplasmatic reticulum or Golgi apparatus. Specific process differs in the way of stimulation. While stimulating cells by TNF leads to releasing of HMGB1 through phosphorylation, stimulation by lipopolysacharide results in HMGB1 releasing dependent on hyper-acetylating of its own lysine residues. This hyper-acetylating processes cause the changes in structure of HMGB1 protein that directly contribute to gathering of HMGB1 in cell's cytoplasm and do not allow its returning into the nucleus of the cell $(25,26)$. HMGB1 is then absorbed into secretory lysosomes in a specific manner. This process is followed by a specific secretion of HMGB1 that depends on extracellular stimulation of leukocyte by lys-phospatidylcholine (LPC). LPC is produced in the area of inflammation later than other contributors of inflammatory response, e.g. IL-1. After all, secretory lysosomes can fuse with cell membrane and HMGB1 is secreted into the extracellular fluid (27).

There are some of the non-immune cells that HMGB1 can be released from, e.g. pituicytes stimulated with IL-1 or TNF (28). Also enterocytes can produce HMGB1 after the cytokine stimulation (29). In addition to stimulation by cytokines, cells like hepatocytes can secrete HMGB1 under hypoxic conditions or during oxidative stress and this secretion is based on changes in calcium level in a cell (30).

HMGB1 like a membrane-bound protein was found also to promote neurite outgrowth and to be involved in migration of some tumour cell lines when situated at the advancing plasma membrane or filopodia (31-33). HMGB1 is also involved in generation of active plasmin and matrix metalloproteinases, that facilitate migration by degrading extracellular matrix components, by binding plasminogen and tissue plasminogen activator (tPA) $(34,35)$. 


\section{HMGB1 receptors RAGE}

HMGB1 can perform its extracellular roles through two types of receptors: Receptor for Advanced Glycation End-products (RAGE) and Toll-Like Receptors (TLR) 2, 4 and 9.

RAGE - the receptor for advanced glycation end-products (AGEs) was initially found in diabetes, renal impairment and disorders that lead to local or systemic oxidative stress. Encoded in the Class III region of the major histocompatibility complex (MHC), RAGE belongs to the immunoglobulin super-family. As it also functions as a pattern recognition receptor (PRR), it is able to recognize a 3-D structure of proteins instead of their amino acid sequence.

RAGE is lowly expressed on endothelial cells, epithelial cells, smooth-muscle cells, neurons. A significantly higher expression of RAGE is found on mature lung type-I pneumocytes than on other differentiated adult cells. Expression in high levels is also easily noticeable on embryonic cells $(39,40)$.

RAGE can interact with many ligands, e.g. AGEs, amyloid $\beta$-peptid as well as with HMGB1, and is capable of binding HMGB1 seven-times tightly than AGEs (41). Two major pathways are activated after ligands have been bound to RAGE - CDC42/ Racl and various MAPKs, both leading to NFאB-dependent transcriptional activity. It was shown that RAGE and HMGB1 interaction in the developing nervous system contributes to neurite outgrowth and cell migration, and that was the first time when RAGE was determined to be the receptor for HMGB1 (42, 43, 92). CDC42/Rac1 pathway activated by HMGB1 is connected with migratory phenotype of neurites and various cancer cells and results in changes in cytoskeleton of the cell (43). As an alternative, there is another way of RAGE signalling that leads through activation of 38 MAPK (mitogen-associated protein-kinase) and Erk1/2. Thereafter, this interactions result in phosphorylation and degradation of $\mathrm{I} \kappa \mathrm{B}$, and in activation of gene expression mediated by NF- $\kappa \mathrm{B}(35,41,93)$. This gene expression contributes to production of molecules that are involved in inflammatory response, i.e. adhesion molecules (ICAM1, VCAM1) and cytokines like TNF, IL-1 and IL-8. Therefore, RAGE activation by HMGB1 is responsible for both initiation and also sustaining of pro-inflammatory phenotype $(44,45,93)$.

Expression of RAGE has been found to be raised in many states due to acute or chronic inflammatory conditions, e.g. chronic renal failure, sepsis, rheumatoid arthritis, inflammatory bowel disease, arteriosclerosis, vasculitis and late diabetic complications (46, 94). Many findings confirm RAGE's important role in innate and adaptive immune system processes $(47,48)$. At first, RAGE was found on the surface of various immune cells like monocytes/ macrophages, neutrophils, dendritic cells, and T and B lymphocytes (49-51). RAGE can interact through $\beta 2$ integrin Mac-1 on leukocytes with endothelial cells, on which it is also expressed like an adhesion receptor and so contributes to recruitment of leukocytes in mouse models of inflammation $(52,53)$. Also numerous extracellular RAGE's ligands are connected with acute or chronic inflammatory responses (54-56). Finally, there is an activation of transcriptional factor NF- $\mathrm{kB}$ and variety of its downstream genes, which are also responsible for the regulation of innate and adaptive immune system $(57,94)$.

\section{Toll-like receptors (TLRs)}

As a member of pattern recognition receptors (PRRs) family, the group of TLRs can recognize damage associated molecular pattern molecules (DAMPs) and microbial molecular patterns (PAMPs - pathogen-associated molecular patterns) and are able to trigger inflammatory immune responses directly against pathogens that carry these molecular patterns $(58,61,62)$.

TLRs are expressed on various cells of the innate immune system including neutrophils, macrophages and dendritic cells, and are also expressed on the surface of endothelial cells and mucosal epithelial cells (63).

Each receptor interaction is specific, i.e. double-stranded RNA is recognized by TLR3, TLR4 can recognize LPS from gramnegative bacteria and TLR5 is activated by bacterial flagellin. Furthermore, single-stranded RNA is recognized by TLR7 and un-methylated $\mathrm{CpG}$ motifs in DNA by TLR9. Finally, microbial peptidoglycans, lipoarabinomannan, lipoproteins, lipoteichoic acid and zymosan are able to activate TLR1, TLR2 and TLR6. Due to their function, some of TLRs are localized in endolysosomal compartments of the cell, like TLR3, TLR7 and TLR9 that can recognize viral nucleic acids, contrary to those that recognize bacterial protein and lipid ligands directly on the cell surface $(59,60,95)$. All TLRs, except TLR3, can signal through myeloid differentiation factor 88 (MyD88) pathway that leads to the activation of MAPKs, extracellular signal regulated kinases and NF- $\mathrm{KB}(59,60)$.

HMGB1 is ligand for TLR2, TLR4 and furthermore for TLR9 $(64,68)$. After HMGB1 signalling, TLR pathways are responsible for the activation of NF- $\kappa \mathrm{B}$ and later production of pro-inflammatory cytokines in macrophages in the area of inflammation, and consequently for recruitment of neutrophils in response to releasing of these cytokines in vivo (65). Anti-tumour T-cell immunity is induced through TLR4 pathway by HMGB1 that comes from cells after dead from chemotherapy $(66,95)$.

Many studies have been speculating about HMGB1 protein's ability to trigger activation of receptors in complexes with DNA. Tian et al. demonstrated that activation of TLR9 pathway is possible after complex of HMGB1 and DNA has been bound to it (68, 96). TLR9 activation by HMGB1 is likely to be mediated rather by complexes of HMGB1 with DNA than by HMGB1 itself. In this way, TLR9 pathway leads in immune cells to maturation and production of cytokines $(68,69)$. Other researches indicated that in some other cell types HMGB1-DNA complexes are able to cause the suppression of immune response (70). In addition to signalling by HMGB1-DNA complexes, HMGB1 bounded to nucleosomes derived from apoptotic cells can interact with TLR2 and is able to induce production of anti-dsDNA and anti-histone IgG antibodies $(67,95)$. Increased pro-inflammatory activity is noticed also after signalling HMGB1 in complexes with other cytokines like IL-1, IFN- $\gamma$, and TNF, in comparison to HMGB1 signalling alone (71). It is still questionable if other HMGB1 complexes or its modifications are necessary for activation of PRR`s pathways (96). 


\section{Physiological and pathological roles of HMGB1}

HMGB1, formerly known as non-histone DNA binding protein, was regarded to have an important function in structural stabilization of nucleosomes and proper regulation of transcription in somatic cell. In addition to its intracellular activities, HMGB1 also acts as a cytokine that activates many different receptors and through multiple downstream pathways induces various specific responses in numerous cell types $(96,97)$.

\section{Effects of HMGB1 on individual cells}

Cultures of monocytes and macrophages were revealed to produce pro-inflammatory cytokines, e.g. TNF, IL-1, IL-1Ra, IL-6, IL-8, MIP-1, but not IL-10 or IL-12 after recombinant HMGB1 had been added (72). Besides, LPS induction lead to monophasic TNF response, while HMGB1 stimulated TNF production seemed to be biphasic with peaks in 4th and 10 th hour $(73,92)$. Also an increase of the adhesive capacity occured after HMGB1stimulation and this appears to be augmented by other pro-inflammatory cytokines $(74,75)$.

In contrast to monocytes, in LPS, activated neutrophils induced the TNF release in 4hrs, HMGB1 lead to TNF peaking just in 60 min $(77,92)$. Stimulation by HMGB1 also lead to an increased interaction between MAC-1 and RAGE that resulted in activation of adhesive and migratory phenotype of neutrophils (53). Under the influence of HMGB1, NAD-(P)-H oxidase and NF- $\kappa$ B were activated, and thus neutrophils were stimulated to produce reactive oxygen species and also production of the pro-inflammatory cytokines was increased $(64,76,77)$.

HMGB1 in dendritic cells lead to higher expression of cell surface markers and increased releasing of pro-inflammatory cytokines as well, so it may play a role in maturation of these cells $(78,79,96)$.

T-cells appeared to increase proliferation, survival and cytokine production as a result of HMGB1 stimulation. Furthermore, Th-1 polarization was evident $(78,80,96)$.

HMGB1 functions as a stimulator of expression of RAGE in endothelial cells. Also pro-inflammatory cytokines (TNF, IL-8 and MCP-1) and regulators of fibrinolytic activity (tPA and PAI) are released from endothelial cells under the effect of HMGB1. Furthermore, the expression of vascular adhesion molecules (ICAM-1 and VCAM-1) was increased on the cell's surface, thereby endothelial cells were able to attract cells that played role in inflammatory response as well as to promote their transition into the area of inflammation. In addition to participation of HMGB1 in the processes of inflammation, there was also local TNF production that contributed to amplification of pro-inflammatory effect of this protein on endothelial cells $(83,92)$.

The expression of inducible nitric oxide synthase was also increased by HMGB1 and so barrier function of epithelial cells was damaged. It was revealed that systemic administration of HMGB1 could impair the barrier function of gut-epithelial cells in mice, resulting in raised permeability of ileal mucosa and in subsequent bacterial invasion into mesenteric lymph nodes $(81,92)$.
HMGB1 is at least as strong stimulator of smooth-muscle cell migration as bFGF is. It also induced cytoskeleton reorganization and thus enabled shape changes of these cells $(88,92)$.

\section{HMGB1, reparative process and regeneration}

Besides its role in the inflammatory process, this protein is further implicated in regeneration that this is another interesting feature of this molecule. Stem cells tend to move towards the area of inflammation under the influence of HMGB1. In this way, HGMB1 contributes to reparative and regenerative tissue changes $(53,84)$. HMGB1 lead to increased myogenesis and angiogenesis in skeletal muscle $(85,96)$. While in normal mice wound healing has been slowed-down as a consequence of inhibition in HMGB1 signalling, topical application of HMGB1 caused an acceleration of this process in diabetic mice, so HMGB1 might also take an important part in diabetic wound healing (86). Moreover, an exogenous HMGB1 directly injected to peri-infarcted area contributed to an increased amount of myocytes inside the area of infarcted cardiomyocytes that went along with an improved outcome confirmed by structural and functional measures $(87,96)$. These examples support an effect of HMGB1 in the regenerative processes.

\section{HMGB1 and atherosclerosis}

An injury of endothelium is essential for the initiation of atherosclerosis as it leads to the attraction of macrophages. Progression of atherosclerosis goes along with prolonged pro-inflammatory response (98). It was revealed that HMGB1 and RAGE were expressed in endothelial cells, smooth muscle cells, and macrophages of atherosclerotic lesions (99). Therefore, up-regulation and secretion of HMGB1 may lead to the intensification of inflammatory response in endothelium lesions and thus promote further atherosclerotic changes (93).

\section{HMGB1 in ischemic and reperfusion injury}

Many factors have been revealed to be involved in pathogenesis of ischemic and reperfusion (IRI) including nitric oxide or plenty of cytokines released under pro-inflammatory conditions in the afflicted area in many organs i.e. heart, brain, kidney or liver $(108,109)$. Recent studies suggested a potential implication of HMGB1 signalling in IRI (110). Ischemia lead to tissue damage and due to these changes high levels of HMGB1 protein were released around the central ischemic area (111). It was demonstrated that HMGB1 was able to stimulate releasing of glutamate and while glutamate-excitotoxicity contributed to pathogenesis of stroke, it is possible that HMGB1 played a substantial role in stroke. Also RAGE has been lately identified as an important receptor implicated in stroke, giving another suggestion about function of HMGB1 protein in this condition (112).

\section{HMGB1 and its role in sepsis and infectious inflammation}

Despite advances in antibiotic therapy and intensive care, sepsis remains the most common cause of death in the intensive care units. 
SIRS (Systemic Inflammatory Response Syndrome) is a systemic inflammatory state triggered by a huge variety of stimuli, i.e. infection, trauma, ischemia, hemorrhage, burns and pancreatitis. SIRS is commonly complicated by multiple organ dysfunction syndrome (MODS), which is a result of SIRS-induced hypotension and disseminated intravascular coagulopathy, and finally can lead to death. The sepsis is a SIRS, in which an infection is the triggering stimulus. Its mortality is close to $30 \%(100,92)$.

In 1999, Wang and colleagues using an animal model revealed that HMGB1 functioned as a mediator of endotoxin-induced lethality (73). Afterwards, Yang with his group described the same increased levels of HMGB1 also in animal CLP-induced (cecal ligation and puncture) model of sepsis as a cause of mortality $(101,102)$.

Participation of HMGB1 in sepsis is interesting because of its later releasing and peaking during inflammatory response in opposite to other pro-inflammatory cytokines, e.g. TNF or IL-1. This was the reason why HMGB1 was known as "late mediator of sepsis". Its levels are raising in $16 \mathrm{hrs}$ and remain significantly elevated for $32 \mathrm{hrs}$ after induction with LPS in mice model (73). There were also studies, in which HMGB1 was revealed to be significantly elevated in serum of septic patients and patients with MODS induced by sepsis. Comparing surviving patients with those who did not survive, a significantly higher serum levels of HMGB1 were in coincidence with a higher mortality in septic patients (73). Furthermore, increased levels of HMGB1 were found in plasma of patients after TNF or other classical pro-inflammatory cytokines have been secreted in early phase of inflammation, it is likely that TNF together with damaged and dying cells were stimuli for release of HMGB1 $(101,103)$.

The exact mechanism of tissue injuring by HMGB1 is not yet completely elucidated. High plasma levels of HMGB1 are regarded to be responsible for epithelial leakage after impairing an intestinal barrier. This is mediated through RAGE pathway (104, 105). Furthermore, the production of ROS (reactive oxygen species) after activation of NAD(P)H-oxidase in neutrophils through TLR4 signalling represents another mechanism of HMGB1 activity in tissue injury $(106,107)$. However, there are still many details that remain to be explained.

\section{HMGB1 and autoimmune diseases}

Pro-inflammatory and immune-stimulatory function of HMGB1 indicates its association with autoimmune diseases, e.g. rheumatoid arthritis (RA) or systemic lupus erythematosus (SLE). HMGB1 levels have been found to be elevated in animal models of experimental arthritis (113) and in synovial fluid of patients with RA, where levels adequate to promote maturation of dendritic cells have been detected $(78,88,115,116)$. In contrast to synovial fluid, HMGB1 levels had no tendency to be elevated in serum or plasma of patients with RA. This finding was most likely caused by interaction of HMGB1 with serum components, which resulted in creation of complexes that restrain HMGB1 to be detected by ELISA (114). Complexes consist of HMGB1 and IgG class antiHMGB1 antibodies, high levels of which have been detected in patients with RA (117).
SLE is another autoimmune disease, in which HMGB1 is implicated. E. Voll with his colleagues (118) suggested a model of immunopathogenesis of SLE, in which impaired phagocytosis of dead cells in patients with SLE $(119,120)$ was accompanied by secondary necrosis of apoptotic cells. This process leads to the release of HMGB1 in complexes with nucleosomes (HMGB1 is tightly bound to the chromatin of apoptotic cells). These complexes are later able to activate dendritic cells and macrophages and consequently the immunological tolerance to nucleosomes and dsDNA is disrupted.

\section{HMGB1 in cancer and metastatic processes}

HMGB1 has been revealed to regulate transcription of a few genes that contribute to growth and spread of tumours, e.g. TNF, BRCA or E-selectin (121-123). Also, HMGB1/RAGE-signalling has been found to be implicated in various cancer diseases (33) like colon cancer $(124,125)$ or prostate cancer (126). Lately, HMGB1 overexpression in tumour endothelial cells has been suggested to be associated with pro-angiogenic and metastatic potential of tumour mass (127). Furthermore, high levels of HMGB1 were accompanied with low differentiation of tumour cells $(128,129)$. Recent studies revealed paradoxical dual effect of HMGB1: in addition to its negative contribution in tumour neo-angiogenesis it also triggered protective anti-neoplastic T-cell responses (130). These findings support the theory that HMGB1 plays an important role in tumour growth and metastatic process. Therefore, further investigation may offer an important target in therapy of cancer diseases.

\section{Therapeutic approach}

There are few approaches in blockage of pathological activities of HMGB1 protein. The variety of antibodies have been used to restrain or reduce cytokine function of HMGB1 (132). Beside these biological agents there is another group - the cytokine-release inhibitory drugs (CRIDs) - that consists of small-molecule compounds like ethyl pyruvate, cholinergic agonists - nicotine and acetylcholine, stearoyl lysophosphatidylcholine and steroidlike pigment tanshinone IIA. These are able to react directly with HMGB1 and thus inhibit its release out of the cells, but they have no influence on individual systemic activities of HMGB1 (133136). Glycyrrhizin have also been revealed to inhibit cytokine function of extracellular HMGB1 $(132,137)$. It does not affect HMGB1 releasing, once HMGB1 has been released out of the cell, glycyrrhizin directly binding to HMGB1 created complexes with it and blocked this way the chemotactic and mitogenic activities $(24,132,137)$.

Due to pro-inflammatory effects of HMGB1, it is important to talk about its inhibition. To do this, a wide range of chemical substances have been studied experimentally. It was found that HSP72, which also plays a role of alarmin by itself, could interestingly inhibit releasing of HMGB1. Original studies revealed that heat shock in macrophages, which were previously stimulated by LPS, could inhibit HMGB1 releasing (36). Furthermore, HSP72 over-expression resulted in inhibited HMGB1 releasing 
from LPS-, TNF-, or oxidative stress-stimulated macrophages. The intracellular cooperation between HMGB1 and HSP72 was likely the reason for this inhibition $(37,38)$.

Also endogenous neuropeptides, vasoactive intestinal peptide and urocortin were revealed to decrease levels of HMGB1 and thus to increase survival when administered in animal model of lethal sepsis $(131,103)$.

\section{References}

1. Goodwin GH, Sanders C, Johns EW. A new group of chromatinassociated proteins with a high content of acidic and basic amino acids. Eur J Biochem 1973; 38: 14-19.

2. Bustin M. Regulation of DNA-dependent activities by the functional motifs of the highmobility-group chromosomal proteins. Mol Cell Biol 1999; 1999; 19: 5237-5246.

3. Rauvala H, Pihlaskari R. Isolation and some characteristics of an adhesive factor of brain that enhances neurite outgrowth in central neurons. J Biol Chem 1987; 262: 16625-16635.

4. Ferrari S, Ronfani L, Calogero S, Bianchi ME. The mouse gene coding for high mobility group 1 protein (HMG1). J Biol Chem 1994; 269: $28803-28808$.

5. Paonessa G, Frank R, Cortese R. Nucleotide sequence of rat liver HMG1 cDNA. Nucleic Acids Res 1987; 15: 9077.

6. Wen L, Huang JK, Johnson BH, Reeck GR. A human placental cDNA clone that encodes nonhistone chromosomal protein HMG-1. Nucleic Acids Res 1989; 17: 1197-1214.

7. Gariboldi M, De Gregorio L, Ferrari S et al. Mapping of the HMG1 gene and of seven related sequences in the mouse. Mamm Genome 1995; 6: $581-585$.

8. Kornblit B, Munthe-Fog L, Petersen SL, Madsen HO, Vindelov L, Garred P. The genetic variation of human HMGB1 gen. Tissue Antigenes 2007; 70: 151-156.

9. Tsuda K, Kikuchi M, Mori K, Waga S, Yoshida M. Primary structure of non-histone protein HMG1 revealed by the nucleotide sequence. Biochemistry 1988; 27: 6159-6163.

10. Thomas JO, Travers AA. HMG1 and 2, and related architectural DNA-binding proteins. Trends Biochem Sci 2001; 6: 167-174.

11. Bustin M, Reeves R. High-mobility-group chromosomal proteins: architectural components that facilitate chromatin function. Prog. Nucleic Acids Res Mol Biol 1996; 54: 35-100.

12. Bianchi ME, Beltrame M, Paonessa G. Specific recognition of cruciform DNA by nuclear protein HMG1. Science 1989; 243: 1056-1059.

13. Bianchi ME, Falciola L, Ferrari S, Lilley DM. The DNA binding protein is composed of two similar segments (HMG boxes), both of which have counterparts in other eukaryotic regulatory proteins. Embo J 1992; 11: $1055-1063$

14. Lotze MT, Tracey KJ. High-mobility group box 1 protein (HMGB1): nuclear weapon in the immune arsenal. Nat Rev Immunol 2005; 5: 331-342.

15. Onate SA, Prendergast $P$, Wagner JP et al. The DNA-bending protein HMG1 enhances progesterone receptor binding to its target DNA sequences. Mol Cell Biol 1994; 14: 3376-3391.

16. Zhang CC, Krieg S, Shapiro DJ. HMG1 stimulates estrogen response element binding by estrogen receptor from stably transfected HeLa cells. Mol Endocrinol 1999; 13: 632-643.
17. Verrier Cs, Roodi N, Yee CJ et al. High-mobility group (HMG) protein HMG-1 and TATA-binding protein-associated factor TAF(II)30 affect estrogen receptor-mediated transcriptional activation. Mol Endocrinol 1997; 11: 1009-1019.

18. Zappavigna V, Falciola L, Citterich MH, Mavilio F, Bianchi ME. HMG1 interacts with HOX proteins and enhances their DNA binding and transcriptional activation. EMBO J 1996; 15: 4981-4991.

19. Sutrias-Grau M, Bianchi ME, Bernues J. High mobility group protein 1 interacts specifically with the core domain of human TATA boxbinding protein and interferes with transcription factor IIB within the pre-initiation complex. J Biol Chem 1999; 274: 1628-1634.

20. Calogero S, Grassi F, Aguzzi A, Voigtlander T, Ferrier P, Ferrari S, Bianchi ME. The lack of chromosomal protein HMG1 does not disrupt cell growth but causes lethal hypoglycaemia in newborn mice. Nat Genet 1999; 22: 276-280.

21. Prasad S, Thakur MK. Age-dependent effects of sodium butyrate and hydrocortisone on acetylation of high mobility group proteins of rat liver. Biochem Int 1988; 16: 375-382.

22. Landsman D, Bustin M. A signature of the HMG-1 box DNA binding essays 1993; 15: 539-546.

23. Mosevitsky MI, Novitskaya VA, Iogannsen MG, Zabezhinsky MA. Tissue specificity of nucleo-cytoplasmic distribution of HMG1 and HMG2 proteins and their probable functions. Eur J Biochem 1989; 185: 303-310.

24. Scaffidi P, Misteli T, Bianchi ME. Release of chromatin protein HMGB1 by necrotic cells triggers inflammation. Nature 2002; 418: 191-195.

25. Bonaldi T, Talamo F, Scaffidi P, Ferrera D, Porto A, Bachi A, Rubartelli A, Agresti A, Bianchi ME. Monocytic cells hyperacetylate chromatin protein HMGB1 to redirect it towards secretion. EMBO J 2003; 22 (20): 5551-5560.

26. Youn JH, Shin JS. Nucleocytoplasmic shuttling of HMGB1 regulated by phosphorylation that redirects it towards secretion. J Immunol 2006; 177: 7889-7897.

27. Gardella S, Andrei C, Ferrera D, Lotti LV, Torrisi MR, Bianchi ME, Rubartelli A. The nuclear protein HMGB1 is secreted by monocytes via a non-classical, vesicle-mediated secretory pathway. EMBO Rep 2002; 3: 995-1001.

28. Wang $\mathbf{H}$ et al. Proinflammatory cytokines (tumor necrosis factor and interleukin 1) stimulate release of high mobility group protein-1 by pituicytes. Surgery 1999; 126: 389-392.

29. Liu $\mathrm{S}$ et al. HMGB1 is secreted by immunostimulated enterocytes and contributes to cytomix-induced hyperpermeability of Caco-2 monolayers. Am J Physiol Cell Physiol 2006; 290: C990-999.

30. Tsung A et al. HMGB1 release induced by liver ischemia involves Toll-like receptor 4 dependent reactive oxygen species production and calcium-mediated signaling. J Exp Med 2007; 204: 2913-2923.

31. Rauvala H, Pihlaskari R. Isolation and some characteristics of adhesive factor of brain that enhances neurite outgrowth in central nerurons. J Biol Chem 1987; 262: 16625-16635.

32. Merenmies J, Pihlaskari R, Laitinen $\mathbf{J}$ et al. 30-kDa heparinbinding protein of brain (amphoterin) involved in neurite outgrowth. Amino acid sequence and localization in the filopodia of the advancing plasma membrane. J Biol Chem 1991; 266: 16722-16729.

33. Parkkinen J, Raulo E, Merenmies J et al. Amphoterin, the 30-kDa protein in a family of HMG1-type polypeptides. Enhanced expression in 
transformed cells, leading edge localization, and interactions with plasminogen activation. J Biol Chem 1993; 268: 19726-19738.

34. Parkkinen J, Rauvala H. Interactions of plasminogen and tissueplasminogen activator (t-PA) with amphoterin. Enhancement oft-PA-catalyzed plasminogen activation by amphoterin. J Biol Chem 1991; 266: 16730-16735.

35. Taguchi A, Blood DC, del Toro G et al. Blockage of RAGE-amphoterin signaling suppresses tumour growth and metastases. Nature 2000; 405: 354-360.

36. Tang $\mathbf{D}$ et al. Heat shock response inhibits release of high mobility group box -1 protein induced by endotoxin in murine maxrophages. Shock 2005; 23: 434-440.

37. Tang $\mathbf{D}$ et al. The anti-inflammatory effects of heat shock protein 72 involve inhibition of high-mobility-group box 1 release and proinflammatory function in macrophages. J Immunol 2007; 179: 1236-1244.

38. Tang $\mathbf{D}$ et al. Nuclear heat shock protein 72 as a negative regulator of oxidative stress (hydrogen peroxide)-induced HMGB1 cytoplasmic translocation and release. J Immunol 2007; 178: 7376-7384.

39. Schmidt AM, Yan SD, Yan SF, Stern DM. The biology of the receptor for advanced glycation end products and its ligands. Biochem Biophys Acta 2000;1498: 99-111.

40. Demling N, Ehrhardt C, Kasper M, Laue M, Knels L, Rieber E. Promotion of cell adherence and spreading: a novel function of RAGE, the highly selective differentiation marker of human alveolar epithelial type I cells. Cell Tissue Res 2006; 323: 475-488.

41. Huttunen HJ, Rauvala H. Amphoterin as an extracellular regulator of cell motility: from discovery to disease. J Intern Med 2004; 255: 351-366.

42. Chou DK, Zhang J, Smith FI. Developmental expression of receptor for advandced glycation end products (RAGE), amphoterin and sulfoglucuronyl (HNK-1) carbohydrate in mouse cerebellum and their role in neurite outgrowth and cell migration. J Neurochem 2004; 90: 1389-1401.

43. Huttunen HJ, Fages C, Rauvala H. Receptors for advanced glycation end products (RAGE)-mediated neurite outgrowth and activation of NF-kappaB require the cytoplasmic domain of the receptor but different downstream signaling pathways. J Biol Chem 1999; 274: 19919-19924.

44. Fiuza C, Bustin M, Talwar $S$ et al. Inflammation-promoting activity of HMGB1 on human microvascular endothelial cells. Blood 2003; 101: 2652-2660.

45. Park JS, Arcaroli J, Yum HK et al. Activation of gene expression in human neutrophils by high mobility group box 1 protein. Am J Physiol Cell Physiol 2003; 284: C870-C879.

46. Bierhaus A, Stern DM, Nawroth PP. RAGE in inflammation: a new therapeutic target? Curr Opin Investig Drugs 2006; 7: 985-991.

47. Clynes R, Moser B, Yan SF, Ramasamy R, Herold K, Schmidt AM. Receptor for AGE (RAGE): weaving tangled webs within the inflammatory response. Curr Mol Med 2007; 7: 743-751.

48. Herold K, Moser B, Chen Y, Zeng S, Yan SF, Ramasamy R, Emond J, Clynes R, Schmidt AM. Receptor for advanced glycation end products (RAGE) in a dash to the rescue: inflammatory signals gone awry in the primal response to stress. J Leukoc Biol 2007; 82: 204-212.

49. Collison KS, Parhar RS, Saleh SS, Meyer BF, Kwaasi AA, Hammami MM, Schmidt AM, Stern DM, Al-Mohanna FA. RAGE-mediated neutrophil dysfunction is evoked by advanced glycation end products (AGEs). J Leukoc Biol 2002; 71: 433-444.

50. Gebhardt C, Riehl A, Durchdewald M, Nemeth J, Furstenberger G, Muller-Decker K, Enk A, Arnold B, Bierhaus A, Nawroth PP, Hess
J, Angel P. RAGE signaling sustains inflammation and promotes tumor development. J Exp Med 2008; 205: 275-285.

51. Chen Y, Akirav EM, Chen W, Henegariu O, Moser B, Desai D, Shen JM, Webster JC, Andrews RC, Mjalli AM, Rothlein R, Schmidt AM, Clynes R, Herold KC. RAGE ligation affects T cell activation and controls T cell differentiation. J Immunol 2008; 181: 4272-4278.

52. Chavakis T, Bierhaus A, Al-Fakhri N, Schneider D, Witte S, Linn T, Nagashima M, Morser J, Arnold B, Preissner KT, Nawroth PP. The pattern recognition receptor (RAGE) is a counterreceptor for leukocyte integrins: a novel pathway for inflammatory cell recruitment. J Exp Med 2003; 198: 1507-1515.

53. Orlova VV, Choi EY, Xie C, Chavakis E, Bierhaus A, Ihanus E, Ballantyne CM, Gahmberg CG, Bianchi ME, Nawroth PP, Chavakis T. A novel pathway of HMGB1-mediated inflammatory cell recruitment that requires Mac-1-integrin. Embo J 2007; 26: 1129-1139.

54. Gebhardt C, Nemeth J, Angel P, Hess J. S100A8 and S100A9 in inflammation and cancer. Biochem Pharmacol 2006; 72: 1622-1631.

55. Foell D, Wittkowski H, Vogl T, Roth J. S100 proteins expressed in phagocytes: a novel group of damage-associated molecular pattern molecules. J Leukoc Biol 2007; 81: 28-37.

56. Bianchi ME, Manfredi AA. High-mobility group box 1 (HMGB1) protein at the crossroads between innate and adaptive immunity. Immunol Rev 2007; 220: 35-46.

57. Bierhaus A, Humpert PM, Morcos M, Wendt T, Chavakis T, Arnold B, Stern DM, Nawroth PP. Understanding RAGE, the receptor for advanced glycation end products. J Mol Med 2005; 83: 876-886.

58. Kawai T, Akira S. Pathogen recognition with Toll-like receptors. Curr Opin Immunol 2008; 17: 338-344.

59. Akira S, Takeda K. Toll-like receptors signaling. Nat Rev Immunol 2004; 4: 499-511.

60. Lee MS, Kim YJ. Signaling pathways downstream of pattern-recognition receptors and their cross talk. Annu Rev Biochem 2007; 76: 447-480.

61. Miyake K. Innate immune sensing of pathogens and danger signals by cell surface Toll-like receptors. Semin Immunol 2007; 19: 3-10.

62. Beutler B. Neo-ligands for innate immune receptors and the etiology of sterile inflammatory disease. Immunol Rev 2007; 220: 113-128.

63. Abreu MT, Arditi M. Innate immunity and toll-like receptors: clinical implications of basic science research. J Pediatr 2004; 144: 421-429.

64. Park JS, Svetkauskaite D, He Q, Kim JY, Strassheim D, Ishizaka A. and Abraham E. Involvement of Toll-like receptors 2 and 4 in cellular activation by high mobility group box 1 protein. J Biol Chem 2004; 279: 7370-7377.

65. van Zoelen MA, Yang H, Florquin S, Meijers JC, Akira S, Arnold B, Nawroth PP, Bierhaus A, Tracey KJ, and van der Poll T. Role of Tolllike receptors 2 and 4 , and the receptor for advanced glycation end products (Rage) in HMGB1 induced inflammation in vivo. Shock 2008; 31: 280-284.

66. Apetoh L, Ghiringhelli F, Tesniere A, Obeid M, Ortiz C, Criollo A, Mignot G, Maiuri MC, Ullrich E, Saulnier P et al. Toll-like receptor 4-dependent contribution of the immune system to anticancer chemotherapy and radiotherapy. Nat Med 2007; 13: 1050-1059.

67. Urbonaviciute V, Furnrohr BG, Meister S, Munoz L, Heycler P, De Marchis F, Bianchi ME, Kirschning C, Wagner H, Manfredi AA et al. Induction of inflammatory and immune responses by HMGB1-nucleosome complexes: implication for the pathogenesis of SLE. J Exp Med 2008; 205: 3007-3018. 
68. Tian $\mathbf{J}$ et al. Toll-like receptor 9-dependent activation by DNA-containing immune complexes is mediated by HMGB1 and RAGE. Nat Immunol 2007; 8: 487-496.

69. Ivanov $\mathbf{S}$ et al. A novel role for HMGB1 in TLR9-mediated inflammatory responses to CpG-DNA. Blood 2007; 110: 1970-1981.

70. Popovic PJ et al. High mobility group B1 protein suppresses the human plasmacytoid dendritic cell response to TLR9 agonists. J Immunol 2006; 177: 8701-8707.

71. Sha Y, Zmijewski J, Xu Z, Abraham E. HMGB1 develops enhanced proinflammatory activity by binding to cytokines. J Immunol 2008; 180 : $2531-2537$.

72. Andersson U, Wang H, Palmblad K, Aveberger AC, Bloom O, Erlandsson-Harris H, Janson A, Kokkola R, Zhang M, Yang H, Tracey KJ. High mobility group 1 protein (HMG-1) stimulates proinflammatory cytokine synthesis in human monocytes. J Exp Med 2000; 192: 565-570.

73. Wang H, Bloom O, Zhang M, Vishnubhakat JM, Ombrellino M, Che J, Frazier A, Yang H, Ivanova S, Borovikova L, Manogue KR, Faist E, Abraham E, Andersson J, Andersson U, Molina PE, Abumrad NN, Sama A, Tracey KJ. HMG-1 as a late mediator of endotoxin lethality in mice. Science 1999; 285 (5425): 248-251.

74. Rouhiainen A et al. Regulation of monocyte migration by amphoterin (HMGB1). Blood 2004; 104: 1174-1182.

75. DeMarco RA, Fink MP, Lotze MT. Monocytes promote natural killer cell interferon gamma production in response to the endogenous danger signal HMGB1. Mol Immunol 2005; 42: 433-444.

76. Fan $\mathbf{J}$ et al. Hemorrhagic schock induces $\mathrm{NAD}(\mathrm{P}) \mathrm{H}$ oxidase activation in neutrophils: role of HMGB1-TLR4 signaling. J Immunol 2007; 178: 6573-6580.

77. Park JS et al. Activation of gene expression in human neutrophils by high mobility group box 1 protein. Am J Physiol Cell Physiol2003; 284: C870-879.

78. Messmer D et al. High mobility group box protein 1: an endogenous signal for dendritic cell maturation and Th1 polarization. J Immunol 2004; 173: 307-313.

79. Yang $\mathbf{D}$ et al. High mobility group box-1 protein induces the migration and activation of human dendritic cells and acts as an alarmin. J Leukoc Biol 2007; 81: 59-66.

80. Dimitriu IE et al. Release of high mobility group box 1 by dendritic cells controls $\mathrm{T}$ cell activation via the receptor for advanced glycation end products. J Immunol 2005; 174: 7506-7515.

81. Sappington PL, Yang R, Yang H, Tracey KJ, Delude RL, Fink MP. HMGB1 B box increases the permeability of Caco-2 enterocytic monolayers and impairs intestinal barrier function in mice. Gastroenterology 2002; 123: 790-802.

82. Degryse B, Bonaldi T, Scaffidi P, Muller S, Resnati M, Sanvito F, Arrigoni G, Bianchi ME. The high mobility group (HMG) boxes of the nuclear protein HMG1 induce chemotaxis and cytoskeleton reorganization in rat smooth-muscle cells. J Cell Biol 2001; 152: 1197-1206.

83. Fiuza C, Bustin M, Talwar S, Tropea M, Gerstenberger E, Shelhamer JH, Suffredini AF. Inflammation-promoting activity of HMGB1 on human microvascular endothelial cells. Blood 2003; 101: 2652-2660.

84. Palumbo R, Bianchi ME. High mobility group box 1 protein, a cue for stem cell recruitment. Biochem Pharmacol 2004; 68: 1165-1170.

85. De MR et al. Multiple effects of high mobility group box protein 1 in skeletal muscle regeneration. Arterioscler Thromb Vasc Biol 2007; 27: 2377-2383.
86. Straino $\mathrm{S}$ et al. High-mobility group box 1 protein in human and murine skin: involvement in wound healing. J Invest Dermatol 2008; [Epub ahead of print].

87. Limana $\mathbf{F}$ et al. Exogenous high-mobility group box 1 protein induces myocardial regeneration after infarction via enhanced cardiac C-kit + cell proliferation and differentiation. Circulat Res 2005; 97: e73-83.

88. Ulloa L, Messmer D. High-mobility group box 1 (HMGB1) protein: Friend or foe. Cytokine \& Growth Factor Rewiews 2006; 17: 189-201.

89. Bianchi ME. Significant (re)location: how to use chromatin and/or abundant proteins as messages of life and death. Trends Cell Biol 2004; 14: 287-293.

90. Dimitriu IE, Baruah P, Manfredi AA, Bianchi ME, Rovere-Querini P. HMGB1: guiding immunity from within. Trends Immunol 2005; 26: 381-387.

91. Savill J, Dransfield I, Gregory C, Haslett C. A blast from the past: clearance of apoptotic cells regulates immune responses. Nat Rev Immunol 2002; 2: 965-975.

92. O'Callaghan A, Wang J, Redmond HP. HMGB1 as a key mediator of tissue response to injury: roles in inflammation and tissue repair. Eur Surg 2006; 38 (4): 283-292.

93. van Beijnum JR, Buurman WA, Griffioen AW. Convergence and amplification of toll-like receptor (TLR) and receptor for advanced glycation end products (RAGE) signaling pathways via high mobility group B1 (HMGB1). Angiogenesis 2008; 11: 91-99.

94. Riehl A, Nemeth J, Angel P, Hess J. The receptor RAGE: Bridging inflammation and cancer. Cell Communication and Signaling 2009; 7: 12.

95. Srikrishna G, Freeze HH. Endogenous damage-associated molecular pattern molecules at the crossroads of inflammation and cancer. Neoplasia 2009; 11 (7): 615-628.

96. Klune et al. HMGB1: Endogenous danger signaling. Mol Med 2008; 14 (7-8): 476-484.

97. Lange SS, Vasquez KM. HMGB1: The Jack-of-all-Trades Protein is a Master DNA Repair Mechanic Mol Carcinog 2009; 48 (7): 571-580.

98. Mullaly SC, Kubes P. Toll gates and traffic arteries: from endothelial TLR2 to atherosclerosis. Circulat Res 2004; 95: 657-659.

99. Kalinina N, Agrotis A, Antropova Y et al. Increased expression of the DNA-binding cytokine HMGB1 in human atherosclerotic lesions: role of activated macrophages and cytokines. Arterioscler Thromb Vasc Biol 2004; 24: 2320-2325.

100. Angus DC et al. Epidemiology of severe sepsisin the United States: analysis of incidence, outcome, and associated costs of care. Crit Care Med 2001; 29: 1303-1310.

101. Yang et al. Reversing established sepsis with antagonists of endogenous HMGB1. Proc Nati Acad Sci USA 2004; 101: 296-301.

102. Fink MP. Neuropeptide modulator of HMGB-1 secretion as potencial therapeutic agents for severe sepsi. 2008.

103. Wang H, Yang H, Czura CJ, Sama AE, Tracey KJ. HMGB1 as a late mediator of lethal systemic inflammation. Am J Respir Crit Care Med 2001; 164: 1768-1773.

104. Yang $\mathbf{R}$ et al. Anti-HMGB1 neutralizing antibody ameliorates gut barrier dysfunction and improves survival after hemorrhagic shock. Mol Med 2006; 12: 105-114.

105. Raman KG, Sappington R, Yang R, Levy RM, Prince JM, Liu S, Watkins SK, Schmidt AM, Billiar TR, Fink MP. The role of RAGE in pathogenesis of intestinal barrier disfunction after hemorrhagic shock. Am J Physiol Gastrointest Liver Physiol 2006; 291: G556-G565. 
106. Fan J, Li Y, Levy RM, Fan JJ, Hackman DJ, Vodovotz Y, Yang H, Tracey KJ, Billiar TR, Wilson MA. Hemorrhagic schock induces $\mathrm{NAD}(\mathrm{P}) \mathrm{H}$ oxidase activation in neutrophils: role of HMGB1-TLR4 signaling. J Immunol 2007; 178: 6573-6580.

107. Rauvala H, Rouhiainen A. Physiological and pathophysiological outcomes of the interactions of HMGB1 with cell surface receptors. Biochim Biophys Acta 2010; 1799: 164-170.

108. Matsuki A, Igawa A, Nozawa T, Nakadate T, Igarashi N, Nonomura M, et al. Early administration of fluvastatin, but not at the onset of ischemia or reperfusion, attenuates myocardial ischemia-reperfusion injury through the nitric oxide pathway rather than its antioxidant property. Circ J 2006; 70: 1643-1649.

109. Hsieh YH, Huang SS, Wei FC, Hung LM. Resveratrol attenuates ischemia-reperfusion-induced leukocyte - endothelial cell adhesive interactions and prolongs allograft survival across the MHC barrier. Circ J 2007; 71: 423-428.

110. Goldstein RS, Gallowitsch-Puerta M, Yang L, Rosas-Ballina M, Huston JM, Czura CJ et al. Elevated high-mobility group box 1 levels in patients with cerebral and myocardial ischemia. Shock 2006; 25: 571-574.

111. Kim JB, Sig Choi J, Yu YM, Nam K, Piao CS, Kim SW, Lee MH, Han PL, Park JS, Lee JK. HMGB1, a novel cytokine-like mediator linking acute neuronal death and delayed neuroinflammation in the postischemic brain. J Neurosci 2006; 26: 6413-6421.

112. Muhammad S, Barakat W, Stoyanov S, Murikinati S, Yang H, Tracey KJ, Bendszus M, Rossetti G, Nawroth PP, Bierhaus A, Schwaninger M. The HMGB1 receptor RAGE mediates ischemic brain damage. J Neurosci 2008; 28: 12023-12031.

113. Andersson U, Erlandsson-Harris H, Yang H, Tracey KJ. HMGB1 as a DNA-binding cytokine. J Leukoc Biol 2002; 72: 1084-1091.

114. Urbonaviciute V, Furnrohr BG, Weber $C$ et al. Factors masking HMGB1 in human serum and plasma. J Leukoc Biol 2007; 81: 67-74.

115. Taniguchi N, Kawahara K, Yone K, Hashiguchi T, Yamakuchi M, Goto M et al. High mobility group box chromosomal protein 1plays a role in the pathogenesis of rheumatoid arthritis as a novel cytokine. Arthritis Rheum 2003; 48: 971-981.

116. Kokkola R, Sundberg E, Ulfgren AK, Palmblad K, Li J, Wang $\mathbf{H}$ et al. High mobility group box chromosomal protein 1: a novel proinflammatory mediator in synovitis. Arthritis Rheum 2002; 46: 2598-2603.

117. Wittemann B, Neuer G, Michels H, Truckenbrodt H, Bautz FA. Auto-antibodies to nonhistone chromosomal proteins HMG-1 and HMG2 in sera of patients with juvenile rheumatoid arthritis. Arthritis Rheum 1990; 33: 1378-1383.

118. Voll RE, Urbonaviciute V, Hermann M, Kalden JR. High mobility group box 1 in the pathogenesis of inflammatory and autoimmune diseases. Isr Med Assoc J 2008; 10 (1): 26-28.

119. Herrmann M, Voll RE, Zoller OM, Hagenhofer M, Ponner BB, Kalden JR. Impaired phagocytosis of apoptotic cell material by monocytederived macrophages from patients with systemic lupus erythematosus. Arthritis Rheum 2008; 41: 1241-1250.

120. Baumann I, Kolowos W, Voll RE, Manger B et al. Impaired uptake of apoptotic cells into tangible body macrophages in germinal centers of patients with systemic lupus erythematosus. Arthritis Rheum 2002; 46: 191-201.

121. Fashena SJ, Reeves R, Ruddle NH. A poly(dA-dT) upstream activating sequence binds high-mobility group box 1 protein and contributes to lymphotoxin (tumor necrosis factor-beta) gene regulation. Mol Cell Biol 1992; 12: 894-903.
122. Thanos D, Maniatis T. The high mobility group protein HMG I(Y) is required for NF-kappa B-dependent virus induction of the human IFNbeta gene. Cell, 1992; 71: 777-789.

123. Baldassarre $\mathbf{G}$ et al. Negative regulation of BRCA1 gene expression by HMGA1 proteins accounts for the reduced BRCA1 protein levels in sporadic breast carcinoma. Moll Cell Biol 2003; 23: 2225-2238.

124. Kuniyasu H, Chihara Y, Takahashi T. Co-expression of receptor for advanced glycation end products and the ligand amphoterin associates closely with metastasis of colorectal cancer. Oncol Rep 2003; 10: 445-448.

125. Sasahira T, Akama Y, Fujii $K$ et al. Expression of receptor for advanced glycation end products and HMGB1/amphoterin in colorectal adenomas. Virchows Arch 2005; 446: 411-415.

126. Kuniyasu H, Chihara $\mathbf{Y}$, Kondo $\mathbf{H}$ et al. Amphoterin induction in prostatic stromal cells by androgen deprivation is associated with metastatic prostate cancer. Oncol Rep 2003; 10: 1863-1868.

127. van Beijnum JR, Dings RP, van der Linden $\mathbf{E}$ et al. Gene expression of tumor angiogenesis dissected: specific targeting of colon cancer angiogenic vasculature. Blood 2006; 108: 2339-2348.

128. Muller S, Ronfani L, Bianchi ME. Regulated expression and subcellular localization of HMGB1, a chromatin protein with a cytokine function. J Intern Med 2004; 255: 332-343.

129. Seyedin SM, Pehrson JR, Cole RD. Loss of chromosomal high mobility group proteins HMG1 and HMG2 when mouse neuroblastoma and Friend erythroleukemia cells become committed to differentiation. Proc Natl Acad Sci USA 1981; 78: 5988-5992.

130. Campana L, Bosurgi L, Rovere-Querini P. HMGB1: a two-headed signal regulating tumor progression and immunity. Curr Opin Immunol 2008; 20: 518-523.

131. Chorny A, Delgado M. Neuropeptides rescue mice from lethal sepsis by downregulating the secretion of the late-acting inflammatory mediator high mobility group box 1. Am J Pathol 2008; 172: 1287-1292.

132. Girard JP. A direct inhibitor of HMGB1 cytokine. Chem Biol 2007; 14 (4): 345-347.

133. Ulloa L, Ochani M, Yang H, Tanovic M, Halperin D, Yang R, Czura CJ, Fink MP, Tracey KJ. Ethyl pyruvate prevents lethality in mice with established lethal sepsis and systemic inflammation. Natl Acad Sci USA 2002; 99: 12351-12356.

134. Wang H, Liao H, Ochani M, Justiniani M, Lin X, Yang L, AlAbed Y, Metz C, Miller EJ, Tracey KJ et al. Cholinergic agonists inhibit HMGB1 release and improve survival in experimental sepsis. Nat Med 2004; 10: 1216-1221.

135. Chen G, Li J, Qiang X, Czura CJ, Ochani M, Ochani K, Ulloa L, Yang H, Tracey KJ, Wang P et al. Suppression of HMGB1 release by stearoyl lysophosphatidylcholine: an additional mechanism for its therapeutic effects in experimental sepsis. J Lipid Res 2005; 46: 623-627.

136. Li W, Li J, Ashok M, Wu R, Chen D, Yang L, Yang H, Tracey KJ, Wang P, Sama AE et al. A cardiovascular drug rescues mice from lethal sepsis by selectively attenuating a late-acting proinflammatory mediator, high mobility group box 1. J Imunol 2007; 178: 2856-3864.

137. Mollica L, De Marchis F, Spitaleri A, Dallacosta C, Pennacchini D, Zamai M, Agresti A, Trisciuoglio L, Musco G, Bianchi ME. Glycyrrhizin binds to high-mobility group box 1 protein and inhibits its cytokine activities. Chem Biol 2007; 14 (4): 345-347.

Received January 14, 2011. Accepted January 9, 2012. 